\title{
A arrecadação do direito de autor na Europa.
}

\author{
Antônio Chaves \\ Catedrático de Direito Civil na Faculdade de \\ Direito da Universidade de São Paulo.
}

Tenho a honra de apresentar a Vossa Excelência o relatório de minha viagem a Las Palmas de Gran Canaria, a fim de tomar parte por ocasião do XXVII Congresso Mundial dos Autores e Compositores, nas sessões dos dias 26 e 27 de Junho último, da Comissão Jurídica e de Legislação da "Confédération Internationale des Sociétés d'Auteurs et Compositeurs", para a qual tive a honra de ser eleito em outubro do ano passado, completando assim o quadro de 21 representantes do mundo inteiro.

Sem ter tido o ensejo, antes de partir, de entrevistar-me pessoalmente com Vossa Excelência, entendi valiosa a oportunidade para estabelecer contacto com as principais sociedades de direitos autorais da Europa, o que me levou, em vez de diretamente a Las Palmas de Gran Canaria, via Lisboa, a Madrid, onde permaneci um dia, seguindo no dia 24 para o Congresso.

Encerrados os trabalhos, visitei Roma, Munich e Paris razão por que o presente relatório é dividido em cinco partes.

Peço antecipadamente escusas pela extensão do mesmo. Os dados materiais que encerra não são próprios de jurista:

* Relatório de viagem apresentado, em data de 27 de julho de 1970, ao Exmo. Sr. Ministro da Justiça, Prof. AlFredo BuZaId. 
são porém indispensáveis para que o jurista possa formar uma idéia da importância e da complexidade do problema da arrecadação dos direitos autorais, não apenas sob o ponto de vista econômico, mas, principalmente sob o ponto de vista social e cultural.

\section{Sociedad General de Autores de España (SGAE)}

O Presidente Víctor Ruíz Iriarte e os principais dirigentes da SGaE estavam ausentes, pois foi justamente sob os seus auspícios que se realizou o XXVII Congresso.

Fui, no entanto, acolhido com a maior fidalguia pelo sr. Miguel Portolez Gonzalez, Chefe da Secretaria, que tudo fêz para responder ao meu questionário por vêzes indiscreto, sôbre as particularidades relativas ao funcionamento da entidade, permitindo-me acompanhar o mecanismo da arrecadação dos direitos de autor, desde a organização dos programas, até a distribuição efetiva do numerário a cada interessado.

A sgae é a única sociedade de autores da Espanha, o que facilita, racionaliza e reduz o custo administrativo da arrecadação e distribuição do direito de autor.

Está instalada num majestoso e originalíssimo prédio, de estilo barroco-catalão, à Rua Fernando VI, $n .^{\circ} 4$, mas já insuficiente para acolher tôdas as repartições, razão por que, ao lado do mesmo foi construído um moderno edifício com oito andares, no subsolo do qual algumas já se encontram instaladas.

A SgaE há cinco anos vem operando pelo sistema de computadores eletrônicos.

Tôdos os cálculos, no que diz respeito à execução musical - parte mais complexa da matéria e que, por isso mesmo, vai ser objeto de preocupação exclusiva do presente relatório - têm seu ponto de partida nos programas de: 

a) execução mecânica;
b) radiodifusão;
c) execução humana;
d) variedades (festas, números de teatro de variedade que não constituam espetáculos domésticos, etc.);
e) reprodução mecânica;
f) direitos de radiodifusão;
g) direitos de televisão.

Com base em geral nos programas das execuções musicais, é organizada a ficha inicial qualificada de "determinação de local."

Dela constam :
a) quantia cobrada;
b) avaliação do programa;
c) número do talão de cobrança;
d) número de fôlha;
e) número de títulos;
f) número de partes (súmula dos títulos), executadas em cada dia do mês;
g) data e local.

Nesta seção conta a SGAE com 10 máquinas perfuradoras, ocupando outros tantos funcionários.

A secção conta ainda com um "listador de verificação", com uma máquina "intérprete", e com um amplo fichário.

Temos aí o trabalho preparatório que permite a passagem para a fase ulterior: a do ordenador (computador eletrônico).

Para cada programa, no qual figuram os nomes dos autores, dos intérpretes e as "partes", existe uma ficha da qual consta o total das "partes" e o total das "pesetas" cor- 
respondentes, bem como uma ficha de títulos, em que figuram os títulos com as respectivas partes.

O ordenador da sGAE, marca IBM, é de capacidade menos que mediana, equivalendo a cêrca de $1 / 25$ das possibilidades dos demais. Assim mesmo opera com 16.000 dados, num determinado instante (fração de segundo), fazendo tôda a divisão e apontando o número de pesetas que corresponde a cada "parte" dentro de cada programa.

São conservados os programas, por cinco anos, e os "listados", extensas listas de dados necessários para os cálculos, por não interessarem ao autor ou ao intérprete, por apenas seis meses.

Para economia de espaço, as fichas são gravadas magnèticamente, à razão de 400.000 por rôlo de fita magnética.

$\mathrm{O}$ ordenador opera com três funcionários.

Encerra o ciclo de operações uma máquina intercaladora de novas peças e uma classificadora.

Bem se percebe a quantidade enorme de mão de obra especializada e cara que êsse sistema permite poupar.

Apenas cêrca de $20 \%$ do arrecadado em matéria de direito de autor e direitos conexos são absorvidos pelas despesas de administração, de acôrdo com as diferentes categorias, além dos impostos e gravames gerais.

\section{XXVII Congresso Mundial dos Autores e Compositores}

Cheguei no dia 24, à noite, em Las Palmas de Gran Canaria, mas apenas no dia 26 tiveram início os trabalhos da Comissão Jurídica e de Legislação, na "Casa de Colón".

$\mathrm{Na}$ ausência justificada do dr. Valerio de SAnctis, foi indicado para assumir a presidência dos trabalhos o dr. Roger Fernay, que abriu a sessão e procedeu às formalidades preliminares, constantes da ordem do dia (anexo n. ${ }^{\circ}$ 1). 
O Sr. Presidente fêz a leitura, em resumo, de uma exposição do dr. VAlerio de SANctis sôbre a evolução do direito de autor no plano internacional (anexo n. ${ }^{\circ} 2$ ).

Seguiu-se um relatório verbal do dr. Claude Jaubert, sôbre as medidas visando favorecer os países em vias de desenvolvimento. É a matéria relativa à revisão do desastroso Protocolo de Estocolmo, que agita e preocupa os especialistas em direito de autor do mundo inteiro, e a qual foram dedicadas as duas sessões dêsse dia: a das 10,00 às 13,00 horas, e a das 16,00 às 19,00 .

O relator fêz um resumo das discussões travadas nas reuniões de Paris e de Genebra do Comité encarregado de preparar o anteprojeto francês para a Convenção Internacional, encarecendo a diferença de atmosfera com relação às anteriores reuniões de Estocolmo e de Washington, parecendo todos animados pelo desejo de sairem da situação.

Do teor das manifestações deduz-se que a idéia da fusão dos dois textos, da Convenção de Berna e da Convenção Universal está completamente abandonada, considerando a grande maioria, se não a totalidade dos congressistas, ponto fundamental a separação.

Na sessão da tarde o Presidente sugeriu, devido à escassez do tempo, que tôdas as questões fôssem reunidas em cinco grupos: I - direitos fundamentais das Convenções Universal e Revista; II - traduções, em conjunto para as duas convenções; III — direito de reprodução; IV -- determinação da acessibilidade à Convenção de Berna para novos membros; V - questões diversas, - seguindo-se animados debates sôbre cada um dos tópicos.

As discussões ocuparam mesmo parte da sessão do dia seguinte, que teve lugar entre 10,00 e 13,00 horas.

Chegou-se, finalmente, ao item 6 da ordem do dia, quando coube ao signatário a palavra para falar sôbre o delicado problema da percepção - melhor diríamos, da não percepção - no Brasil, do direito de autor em matéria 
de músicas de filmes cinematográficos, decorrentes da publicação do decreto-lei 980, de 20 de outubro de 1969.

Pareceu a Vossa Excelência - no que me pus logo de acôrdo, pois eram êsses os meus sentimentos - que não ficaria bem a um representante, senão oficial, pelo menos oficioso do Brasil, levantar, ao estrangeiro, o problema da inconstitucionalidade dêsse diploma legislativo.

Eliminei, por isso, na leitura que fiz do "rapport" enviado com muita antecedência quaiquer expressões que pudessem afetar os brios da nossa nacionalidade, o que justifiquei com a escassez do tempo e com o fato de ter sido já determinado por Vossa Excelência um estudo em profundidade da matéria.

O representante de Portugal, dr. Luiz Francisco Rebello pediu a palavra para cumprimentar o orador que acabava de falar, cujos méritos entendeu que podia ressaltar nessa primeira oportunidade em que comparecia a uma reunião da Comissão Jurídica e de Legislação da cISAC, propondo fôssem encaminhadas às autoridades brasileiras moções que expressassem os sentimentos unânimes dos membros presentes no sentido da urgência da suspensão do referido decreto.

À manifestação associou-se o próprio Presidente, que também se referiu à pessoa do signatário com palavras elogiosas, afirmando que o doutor Rebello se havia antecipado a uma iniciativa que êle mesmo pretendia tomar.

Generalizaram-se, durante cêrca de 45 minutos, debates, interpelações e pedidos de explicações, ficando finalmente decidido que seriam encaminhados telegramas, em nome da Confederação Internacional das Sociedades de Autores e Compositores, e, pois, pràticamente, em nome dos autores e compositores do mundo inteiro, ao Excelentíssimo Senhor Presidente da República e a Vossa Excelência, encarecendo a urgência de providências da suspensão dos efeitos de um diploma legal que contraria flagrantemente todos os compromissos assumidos pelo Brasil ao assinar as Convenções de Berna e de Washington. 
Foi lido, em seguida, um relatório do Prof. Walter Dernberg sôbre a revisão do Copyright nos Estados Unidos (anexo n. ${ }^{\circ}$ 4). Os Profs. Desbois e Carlos Mouchet teceram comentários, respectivamente, sôbre a lei grega (anexo n. ${ }^{\circ}$ 5) e sôbre o Projeto de Lei de direito de autor da Argentina, que submeteram também a incisivas críticas.

Finalmente, o sr. Victor Hazan fêz um estudo sôbre a evolução do direito de autor em Israel.

Às 13,00 horas foram encerrados os trabalhos, sem que tivessem sido abordados itens importantes da pauta, como o relatório do sr. Denis de Freitas, que apesar das ressonâncias lusitanas é inglês, sôbre os sistemas de gravações electro-video (anexo n. ${ }^{\circ}$ 6), e o apresentado pela JASRAC sôbre a nova lei japonesa sôbre Direito de Autor (anexo n. ${ }^{\circ}$ ), a serem abordados em nova reunião, já marcada para outubro, possivelmente em Paris.

\section{Società Italiana Degli Autori ed Editori (SIAE)}

No dia 2 de Julho às 10,00 horas em companhia do dr. Daniel Rocha, Diretor da Sociedade Brasileira de Autores Teatrais (SBAT) e Assessor do Govêrno nas recentes reuniões para a revisão das Convenções de Berna e da Unesco em Paris, Genebra e Washington, do sr. Emilıo Vitale, da Irmãos Vitale S. A. Indústria e Comércio, editora gráfica (Editora de Música e de "Lex") e fonográfica (Copacabana), e conselheiro suplente do Serviço de Defesa do Direito Autoral (SdDa), e do sr. Newton Teixeira, DiretorTesoureiro da Sociedade Brasileira de Autores e Compositores de Música, todos delegados brasileiros ao Congresso de Las Palmas, estive em visita à sede da SiaE, no Viale della Letteratura (Eur).

Fomos recepcionados efusivamente pelo dr. Leonello Cecchini, Diretor Central da Secção, que nos deu, inicialmente, um apanhado histórico, das funções e da importância da Siae. 
Tem ela, efetivamente, proporções de um verdadeiro ministério, como resulta do número de funcionários efetivos, cêrca de 1250; do total de direitos que arrecada, 16 bilhões de liras em 1968, 18 bilhões em 1969, correspondendo a 30 milhões de dólares, dado impressionante, especialmente quando comparado ao total arrecadado no Brasil no ano passado, que atingiu apenas uma décima parte: 3 milhões de dólares, e que êste ano vai sofrer o desfalque da não arrecadação dos direitos autorais em matéria de cinematografia; das proporções dos prédios que ocupa: um com cinco andares, com 75 salas cada, e outro, de dois andares, onde foi instalado o computador eletrônico.

Os 16 bilhões arrecadados em 1968 provieram das seguintes fontes:

$$
\begin{aligned}
& 33 \% \text { - manifestações dançantes, } \\
& 18 \% \text { - filmes cinematográficos, } \\
& 26 \% \text { - radiodifusão e televisão, } \\
& 16 \% \text { - repertório geral (revistas de variedade, concer- } \\
& \quad \text { tos, instrumentos mecânicos, bandas), } \\
& 7 \% \text { - repertórios estrangeiros. }
\end{aligned}
$$

Êsses dados ficam naturalmente sujeitos a oscilações, estando previsto para o ano próximo um importante incremento decorrente dos direitos fonográficos.

A relevância do direito de autor em matéria cinematográfica resulta dessa contribuição de $18 \%$ sổbre o total. Na Itália a cobrança é feita "a forfait", na percentagem de $2,10 \%$ sôbre o valor da entrada do cinema, considerada pequena, mas incomparàvelmente mais satisfatória do que a de $0,50 \%$ atribuida no Brasil pelo decreto-lei 980 .

Assinalem-se, além dessas, duas diferenças fundamentais:

a) na Itália o direito é efetivamente arrecadado e escrupulosamente distribuido; 
b) na Itália a produção de filmes, e portanto, a retribuição dos autores, compositores e interpretes é incomparàvelmente maior.

Organização. A SiaE não é nem estatal nem paraestatal. Tem, no entanto, exclusividade de mediação em matéria de direitos autorais e conexos, bem como a exclusividade da representação para os países estrangeiros, não podendo sofrer a concorrência de qualquer outra sociedade congênere, como ocorre, já foi visto, na Espanha com relação à SGAE.

E formada por mais de 10.000 inscritos, entre autores, compositores, editores, etc., e 800 sócios.

E fundamental essa distinção entre as duas categorias: sòmente podem ser sócios os que alcançam uma certa importância pela sua produção intelectual ou pela sua contribuição cultural ou artística.

Chegar ao "status" de sócio oferece três vantagens fundamentais :

a) permite exercer o direito de voto para a constituição das Comissões Técnicas, Conselhos de Administração e Disciplinar;

b) autoriza ser eleito para um dêsses cargos;

c) possibilita obter aposentadoria ao atingir os 60 anos, com 180.000 liras por 13 meses ao ano.

Já os simplesmente inscritos gozam vantagens bem menores: só alcançam a aposentadoria aos 35 anos de inscrição ou 70 anos de idade, mediante a ajuda de 25.000 liras por 12 meses ao ano.

Para ser inscrito numa determinada categoria, p. ex. de editor, é preciso apresentar provas de certa profissionalidade: determinado número de composições impressas, obedecendo a requisitos pré-fixados.

Apenas excepcionalmente é admitida a inscrição de súditos não italianos, que não poderão estar inscritos em sociedades estrangeiras, e que comprovem estar residindo no país desde há determinado tempo. 
A SiaE é chefiada por um Presidente, que a representa legalmente, e gerida por um Conselho de Administração, constituído de 9 elementos. Três representam os autores (sendo um compositor musical, um autor dramático e um autor de obra literária); três representam os editores (um de música, um de obra literária e um de obra cinematográfica) ; dois são representantes ministeriais (um do Presidente do Conselho de Ministros e outro do Ministério da Economia e Finanças); e o próprio Presidente, que é sempre um autor, eleito pela assembléia dos sócios e nomeado pelo Presidente da República.

Existem várias Comissões de Secção: de Música, de Teatro (Dor isto é dramático, operetas e revistas), de Obras Literárias; de Obras de Arte Figurativa, de Cinema, reunindo-se, ordináriamente, uma vez por ano.

Existe também uma Consultoria Legal, presidida pelo Presidente da Sociedade, da qual fazem parte um representante do Ministério das Finanças, um do Presidente do Conselho de Ministros, um do Departamento da Propriedade Literária, um do Ministério da Pública Instrução e quatro juristas especializados em matéria de direito de direito de autor, nomeados pela assembléia de Comissões de Secção cada três anos.

Existem ainda uma Comissão de Recursos, um Diretor Geral e um Conselheiro Jurídico, que também é o diretor da Revista Oficial da SIAE: Il Diritto di Autore.

Administração. A administração da SIAE, complexa pela natureza das suas atribuições, sofre ainda o encargo que lhe é atribuído pelo Estado da arrecadação de determinados impostos, tributos e contribuições.

Fundamental, para os autores e intérpretes, é o custo da arrecadação e distribuição de seus direitos. Varia êle de acôrdo com a categoria. Assim, cobra a SiaE, em matéria de:

Teatro $-10 \%$

Rádio e televisão $-20 \%$ 


\section{Bailes - $28 \%$ \\ Estereo - 5\%}

Contribuição para o Estado - 5\%

A arrecadação em prol do Estado é efetuada a preço de custo. Mas o encargo é compensado pela vantagem de proporcionar à Entidade a fôrça e o prestígio de um verdadeiro agente estatal.

Convirá para o Brasil um sistema tão complexo e tão minucioso? Compensará manter, ainda que inicialmente, em proporções, numerosos funcionários, pagar aluguel de máquinas custosas para prover à distribuição rigorosa dos, cêrca, de 14 milhões de cruzeiros de direitos de autor musical atualmente arrecadados no Brasil?

Não quis o dr. Leonello Cecchini pronunciar-se. Reconhece existirem setores que são mais onerosos do que outros: assim, por exemplo, $20 \%$ do trabalho desenvolvido é consumido na distribuição de apenas $5 \%$ do total representado pelas cobranças relativas aos bailes.

Mas os inscritos e sócios estão há muitos anos acostumados a êsse sistema, e dificilmente aceitariam um diferente, embora em outros países, como na França e na Alemanha, as retribuições, pelo menos em parte, sejam feitas por "amostras", sondagens ou padrões, sistema Gallup.

A própria SiaE abre exceções ao princípio, que denomina de "capilaridade" da arrecadação e pagamento dos direitos de autor e intérprete, que prevalece integralmente em outros setores, como o rádio e a televisão, em que a gravação de todos os programas permite uma verificação, minuto por minuto, de tôdas as músicas e obras executadas.

Para determinadas modalidades, existe opção entre dois sistemas:

a) "a punteggio". Nas execuções cujo valor, em matéria de direito de autor, não exceda 10.000 liras, o respectivo montante é dividido pelo número de obras, estabelecendose uma média, que é atribuída a cada uma das obras executadas; 
b) por qüota. Leva em conta, nas execuções de maior valor, uma importância fixa, que é dividida pelo número de peças. Assim, se um salão de baile executa 50 peças, e deve pagar a importância fixa de 100.000 liras, divide-se êsse montante pelo número de peças, o que dará um total de 2.000 liras por peça.

O número de programas por qüota é pequeno, não chegando a $30 \%$ da arrecadação total, o que facilita sua fiscalização.

A SiaE, sempre que pode, faz acôrdos com tôdas as categorias de interessados, evitando, por essa forma, acusações de prepotência nas decisões que toma.

O sistema de "capilaridade" é mantido com relação à radiodifusão, à televisão, aos filmes, às revistas de variedade, e para todos os demais setores em que não atinja grande desenvolvimento a cobrança dos direitos.

Aconselha o dr. Cecchini, antes de chegar-se a uma solução definitiva, um estudo acurado da estrutura legal e da organização teórica a ser alvitrada que deverá procurar, de qualquer maneira, restringir a uma só as sociedades arrecadadoras para o País, a fim de reduzir os custos de operação.

Passou então a fazer-nos companhia o dr. Mario Fabiani, professor universitário e Vice-Diretor Central.

Entre numerosos outros detalhes, que seria impossível reproduzir neste relatório, esclareceu que de acôrdo com os artigos 180 da Lei Italiana, 10 e seguintes do estatuto e 27 do regulamento do estatuto, na retribuição dos proventos deve ser sempre reservada uma qüota ao autor, o que significa não ser admitida a validade da cessão total dos seus direitos.

Existe, por outro lado, um encadeamento bem definido de responsabilidades: pela exibição do programa das obras a serem executadas, pelo sistema de reprodução; "in vigilando" dos executantes do programa e supletiva do proprietário do estabelecimento. 
Também são protegidos os títulos da obra, nos têrmos dos artigos 100 da lei e 31 do regulamento.

Não é a SIAE depositária de qualquer arquivamento de contratos, nem recebe obras em depósito.

Enquanto que para as criações de autores vivos cobra $10 \%$, para as de domínio público cobra $5 \%$ sôbre o preço bruto arrecadado.

Visitas às secções. Passamos então a percorrer as diversas secções.

O "Ufficio Programmi", como sempre, é o ponto fundamental. Já ficou consignado que perfaz 1250, o número de funcionários efetivos da SiaE. Dêles, cêrca de 650 trabalham junto à Direção Geral, e os demais 600 no interior. Muitos dêstes últimos fazem parte, no entanto, do quadro de agentes locais, que são 2.000 , operando na base de percentagem. Há, ainda, 20 "Direzioni di Sedi" regionais, espécie de agencias ou sucursais, nas cidades mais importantes, contando com entre 10 a 50 funcionários.

A percentagem de remuneração varia, conforme a natureza da obra ou do trabalho, indo de um máximo de $10 \%$ (música) a um mínimo de 2 ou mesmo 1\% (direitos erariais).

A secção programas, como ocorre na Espanha e em todos os países devidamente aparelhados, é tôda mecanizada. Conta com uma máquina de retomada de microfilmes : "Microfilm Fotostat", italiana; com capacidade de fazer 120 microfilmes por minuto; com uma "sviluppatrice", máquina reveladora, marca "Omac"; também fabricada no país, e um visor-leitor "Agfa".

Cada mês são microfilmados de 40 a 50.000 programas, 2500 em cada rôlo a uma média de 30 rolos por mês, que são conservados por 3 anos depois de remetidas as retribuições para as sociedades estrangeiras.

Há, ainda, a Secção Cortes dos Programas, o que é feito por meio de uma guilhotina, que os reparte em 36 pedaços, em cada um dos quais uma máquina cortadora e carim- 
badora: "tickometer", carimba o mês e ano e o gênero da execução, completando assim os demais elementos: nome do autor e da composição, dia da execução e montante em liras que cada cupão já continha.

Secção coordenação e seleção das cédulas. No dia seguinte prosseguiram as explicações. A secção, como o nome indica, encarrega-se da seleção das cédulas por compositor e por obra, levada a efeito manualmente por 30 funcionários, de maneira a permitir a verificação do total do importe devido a cada autor, compositor ou intérprete.

As cédulas, depois de distribuídas de acôrdo com a sua composição, já contendo "uma qüota", cujo valor é estabelecido em função de diversos elementos: categoria do local em que é executada, de maior ou menor luxo; importância, etc., são agrupadas de acôrdo com a espécie. Uma só composição, tal seja a sua popularidade, pode encher 3 ou 4 gavetas de aço do arquivo. Por ocasião do "riepilogo", isto é, do resumo, faz-se o agrupamento geral por autor e por composição.

Está então a contabilidade habilitada a efetuar a remessa das quantias correspondentes, o que faz duas vêzes ao ano, em geral nos meses de abril e outubro.

A importância da secção música é revelada pelo número de funcionários que ocupa na sede central: 150, e pelo número de salas que ocupam: 150, totalizando dois andares do prédio.

As obras musicais são distribuídas em 4 classes. A classe terceira é relativa à utilização radiofônica e televisiva. Seu contrôle e verificação são muito fáceis pois existe uma única estação em todo território italiano: RaI.

Envia, ela, quinzenalmente à SIAE, programas minuciosos, com indicação de cada compositor, cada obra, hora de inicio, e duração em minutos e segundos acompanhados de uma gravação total, minuto por minuto, para permitir a sua verificação. Esses elementos são elaborados pela secção e transformados num documento interno mecânico fabulado, ou lista mecanográfica. 
Chega-se assim à conclusão, por exemplo, que no dia 21 de dezembro de 1969 "Tosca" de Puccini foi executada durante 55 minutos. Como extrair dêsses dados a retribuição devida, uma vez que existe domínio público pago?

Estabelecendo-se a relação entre a duração e um certo coeficiente, e multiplicando-se os dois elementos, temos um total de, digamos, 1650 "punti", que serão somados aos relativos às demais composições do mesmo autor cujo nome está representado pelo número de uma cédula, no caso, 12.993, totalizando pontos relativos às execuções durante 6 meses ou 1 ano.

Outro exemplo. A composição "Notte", de ADamo, foi executada no dia 3 de janeiro de 1969 duas vêzes: uma durante 27 segundos, outra durante $29 . \quad$ o centro mecanográfico apurou que até o fim do ano houve 27 execuções, atribuindo-lhe 61629 pontos.

A terceira classe é constituída pela Rádio e pela Televisão, e obedece aos mesmos critérios.

Uma vez inscritos os montantes nos resumos, os dados são transcritos numa cédula mecanográfica, com o respectivo montante já anotado, fazendo afinal o cérebro eletrônico a prestação de contas para cada um dos inscritos, para cada autor, de 6 em 6 meses, ou, se tratando de rádio, de ano em ano.

A prestação de contas é enviada pelo correio, uma vez que o estatuto da SraE estabelece que o autor deve dar o seu enderêço, e, se não o tiver, deve ser considerado como tal o da própria SiaE.

A segunda classe é constituída pelos filmes cinematográficos, cujos dados são providos diretamente ao centro mecanográfico, sempre pelo mesmo critério.

No prédio anexo visitamos a sala de perfuração, com suas 14 máquinas e seus 14 funcionários correspondentes.

Acaba de ser instalado o sistema 360/30 Iвм a discos, que concentra todo trabalho realizado. 
Terminada a visita, despedímo-nos e muito agradecemos ao dr. Leonello Cecchini a boa vontade com que nos proporcionou todos os dados.

\section{Gesellschaft fur musikalische aufführung und mechanische vervielfaltigungsrechte (GEMA).}

O dia todo de segunda-feira, 29 de julho, foi consagrado à visita à GEMA, cuja denominação corresponde à “Sociedade para o Direito de Execução Pública e Reprodução Mecânica Relativas às Obras Musicais".

Ocupa um amplo prédio de 5 andares, 8 München 2, Herwog-Wilhelm-Strasse 28, tendo outra séde em 1 Berlin 30, Bayreuther Strasse 37/38.

$\mathrm{Na}$ Alemanha Ocidental existem outras duas sociedades de direitos autorais: a Gesellschaft zur Verwertung von Leistungsschutzrechten (GvL — Sociedade para a Gerência dos Direitos de Prestação de Serviços, ou seja Direitos de Produtores Fonográficos e Artistas Executantes, 42 Hamburg 52, Charlotte-Niese-Strasse 8) e Verwertungsgesellschaft Wort (VG WorT - Sociedade de Gerência de obras literárias 8 München 2, Damenstiftstrasse 7).

Nota-se na GEma uma grande preocupação no que diz respeito à simplificação do setor contabilístico.

Os serviços estão divididos nas duas sédes: a de Münich só cuida dos direitos mecânicos e dos que vêm do estrangeiro, centralizando também a direção financeira, enquanto que a de Berlim, que é a "oficial", concentra todos os demais serviços de repartição dos direitos autorais: rádio, televisão, música ligeira, inclusive por meios mecânicos, música sinfônica e filmes sonoros.

No impedimento ocasional do dr. Erich Schulze, fomos muito bem recebidos pelo sr. Wolfgang Schiedung, Diretor do Serviço Estrangeiro, que passou o dia inteiro conosco.

Explicou-nos que na Alemanha Ocidental qualquer pessoa pode fundar outra sociedade de direitos autorais. Mas 
precisa obter autorização do registro de Patentes, com obediência aos reçuisitos estabelecidos pela lei de 9-9-1965.

Organização. Os destinos da GEMa são determinados pela Assembléia Geral dos Membros com direito a voto. Existem três categorias de participantes:

1. Titulares de direitos representados: meros administrados, sem direito a voto ou de participação nas atividades direcionais;

2. Membros extraordinários: são os de maior número, cêrca de 6.000 , em geral jovens compositores, cessionários ou sucessores.

Têm de preencher certas condições, como a de ter percebido determinada quantia a título de direitos autorais, durante alguns anos, para passarem a

3. membros ordinários: aproximadamente 1.000 .

A Assembléia Geral é constituida pelos sócios ordinários, que, para qualquer decisão modificadora dos estatutos ou do critério de distribuição, deverão chegar a uma decisão unânime das três categorias ou grupos: compositores, editores e letristas.

Em cada categoria, as decisões são tomadas por $2 / 3$; na Assembléia Geral, por unanimidade. Cada um dos grupos elege sua representação no Conselho de Vigilância, constituído por seis elementos dos compositores, cinco dos editores e quatro letristas.

O Conselho de Vigilância elege também o Presidente e Diretor Geral da Sociedade, responsável pela administração da mesma, funções essas que podem ser atribuídas a duas pessoas.

O Conselho de Vigilância (que não é bem Conselho Fiscal, pois não controla os atos do Presidente) elege as Comissões :

1. Econômica, que verifica a gerência da Sociedade;

2. De obras; 
3. De taxação,

e tôdas as demais cuja a constituição for considerada útil, como, por exemplo, quando surge a necessidade de modificar o contrato estabelecido com a emprêsa de televisão, etc..

Existem ainda:

Secretaria Geral, com as sub-secções do Secretário Chefe, da Administração, Geral, e dos Serviços IвM;

Serviços (admissão, troca de secções, etc.);

Revisão e Organização;

Percepcão dos Direitos Mecânicos e Fonográficos (conclusão de contratos com produtores de discos);

Relações com a Radiodifusão (preparo dos contratos);

Serviço jurídico, constituído por um só advogado-chefe e diversos funcionários;

Serviço de Pessoal;

Direção de Finanças (Contabilidade Geral, Contabilidade dos Membros, Caixa);

Serviço Estrangeiro, (que se encarrega de repartição dos direitos que provêm do estrangeiro e constitui a central internacional de repartições);

Representações nas cidades mais importantes para Gema: Bruxelas, Buenos Aires, Estambul, Copenhague, Londres, etc.;

Serviço de Documentação (Nacional e Estrangeira) que conta com um musicólogo;

Distribuição dos Direitos, dividida em Rádio e Televisão, Direito de Reprodução Mecânica, Música leve, Música sinfônica e filmes sonoros.

A GEMA, também não é estatal, nem sequer para-estatal, não sofrendo qualquer interferência do Estado, devendo apenas obedecer às determinações da referida lei de 9-9-1965.

Uma vez publicadas suas tarifas no Diário Oficial, são ai assinaladas tôdas as modificações.

Os direitos são calculados, para facilitar as operações, em duodécimos. 
Um editor jamais poderá ter mais do que $6 / 12$, em se tratando de obra de um só autor.

Se forem mais de um os autores, caberá pelo menos $5 / 12$ ao compositor da música; $3 / 12$ ao letrista e $4 / 12$ ao editor originário.

Para contratos com estrangeiros, permite-se que o editor tenha até $6 / 12$, que pode ceder total ou parcialmente, mas que em geral divide pela metade com o cessionário estrangeiro.

De acôrdo com o regulamento de 24 e 25-6-1969, em se tratando de uma cessão da Alemanha para o estrangeiro, pode se escolher uma destas três modalidades:

a) 6/12 para todos os autores interessados (compositor, autor, sub-autor, arranjador, etc.);

$3 / 12$ para o editor;

3/12 para o cessionário do editor no estrangeiro;

b) $6 / 12$ para todos os criadores intelectuais;

2/12 para o editor originário;

4/12 para o sub-diretor;

c) 6/12 para todos os criadores intelectuais;

4/12 para o editor originário;

2/12 para o sub-editor.

Em se tratando de obras estrangeiras, se forem editadas na Alemanha, aplica-se a mesma chave, com o seguinte acréscimo :

6/12 para todos os cessionários e sucessores originários;

6/12 para todos os subcessionários ou sucessores.

Arrecadação, Administração e Distribuição. A Gena conta com apenas 900 funcionários no país, dos quais 400 em Berlim e Munich, e os demais nas direções regionais, 
nenhum dos quais percebe remuneração mediante percentagem.

Para o Estado, a GEMA cobra sòmente a nova taxa sôbre o valor acrescido, estabelecida pela Comunidade Européia, de $11 \%$ sôbre o valor de qualquer autorização, e cujo montante pode ser deduzido dos impostos devidos pela Gema ao Estado.

A soma arrecadada em 1969 foi de Dm 167.261.000, correspondente a perto de 50 milhões de dolares, registrando-se sensivel aumento com relação ao ano anterior, devido, principalmente ao desenvolvimento do direito mecânico.

Para êsse total contribuíram:

Radiodifusão e Televisão (para os dois direitos de emissão e mecânico) . $\quad 34 \%$

Tôdas as demais reproduções mecânicas ( $31 \%$ indústria de discos; $1 \%$ gravações particulares, pequenas indústrias, etc.) $32 \%$

Música viva (concêrtos, músicas ligeiras) - $12 \%$

Música executada por meios mecânicos . $8 \%$

Direitos recebidos do estrangeiro . $\quad 8 \%$

Outras receitas (comissão para percepção em teatros; etc.)

Filmes ...

As despesas gerais de administração, que em 1960 eram de $15,8 \%$, foram sendo sucessivamente reduzidas, até, chegarem a apenas $12,4 \%$ no ano passado.

O surpreendentemente baixo custo de administração só é possível por contar a GEMA com contratos generosos com a radiodifusão e com a indústria fonográfica, que lhe garantem $66 \%$ sôbre as percepções.

Não podendo ser controlado o comparecimento às salas de exibições cinematográficas, foi necessário estabelecer 
uma tarifa fixa que leve em conta o número de lugares, o número de execuções e a categoria do estabelecimento.

Os últimos anos registraram uma evolução explosiva, principalmente em matéria de discos, que de 1968 para 1969 proporcionaram um aumento de direitos autorais de mais de $20 \%$, tendo tido também a indústria fonográfica um aumento de quase $20 \%$.

Nos demais setores, com exclusão do disco, o aumento foi de $12 \%$, o que é extraordinário num país que não sofre inflação.

O direito mecânico tem taxas fixas de administração, que compensam as despesas e permitem diminuir o custo dos outros setores.

Para os bailes e saraus leva-se em conta, entre numerosos outros fatores, a importância das cidades.

A diferença de várias percentagens, com relação à Itália, explica-se pelo fato de, na Alemanha Ocidental, cobrar a GEMA também direitos fonográficos, o que não ocorre com a Siae. Na verdade, ainda existe a Sedrim, Società Esercizio Diritti Riproduzione Meccanica, Via A. Bordoni, 32, I-20124 Milano, embora com tendência de ser absorvida por aquela.

Assinale-se que a lei alemã, apesar de recente, vai ser reformulada em dois pontos principais: no que estabelece isenção de direitos autorais para a publicação de livros escolares, e no que diz respeito à execução gratuita de música nas igrejas e pelas bandas militares.

Cobrança de direitos. Existem duas tarifas: normais, para os particulares e as entidades que não estão consorciadas (avulsas); e preferenciais, para as firmas que se agrupam em organizações.

Assim, por exemplo, a Associação Alemã de Esporte, da qual dependem milhares de associações grandes e pequenas de futebol, conclui um contrato-tipo que estabelece as condições de uso para a música controlada pela Gema. A associação-mãe estipula com cada uma das organizações 
a ela vinculadas um contrato definitivo, obtendo tôdas, por essa forma, um abatimento de $20 \%$.

Existem mais de 300 contratos-tipo: com a Associação Alemã de Restaurantes e Cafés, com a Igreja Católica, com a Igreja Protestante, com a dos Empresários de Espetáculos de Variedades, com a Associação do Cinema, com a Organização das grandes firmas industriais que fazem produzir filmes publicitários, com empresários de concertos, com associações de teatros, com as estradas de ferro, com os bombeiros, com os sindicatos, com as associações municipais, com as emprêsas de ônibus, etc.

Das emprêsas de aviação são cobrados 1,50 marcos por ano e por avião, para a permissão de fazer uso da música tão sòmente por ocasião da decolagem e da aterrisagem, com a condição de não transmití-la durante o vôo. Vai ser renovado o contrato antigo que existe há oito ou nove anos. Pretende-se estendê-lo também à projeção de filmes durante o vôo.

Algumas situações apresentam problemas particulares. Assim, por exemplo, as "juke-boxes" e as audições radiofônicas em estabelecimento público: bares, cafés, etc., em que não há possibilidade de um programa prévio

A secção específica de distribuição da GEMA, estabelece uma qüota de tudo o que é recebido durante um ano, atribuindo:

$40 \%$ à execução por rádio;

$60 \%$ à execução de músicas ligeiras de obras que sairam em discos no período anterior de um ano.

Assim, se para a música ligeira são calculados 600 pontos, poderão êles ser atribuídos mais uma vez.

Os usuários que se utilizam de programas, deverão, depois, entregá-los a Gema, que todavia não tem, por lei, o direito de exigi-los, contando apenas com a obrigação contratual que, se fôr desobedecida, implicará numa multa de 10 marcos. 
A música sinfônica é executada $100 \%$ na base de programas.

Já a música ligeira fornece à GEMA 80.000 programas por ano, o que perfaz um total de 70 a $80 \%$.

Com relação à radiodifusão e à televisão registra-se uma inovação interessante e muito importante para reduzir os custos administrativos: os programas já vêm discriminados em fichas perfuradas e prontas para serem submetidas a computadores eletrônicos.

São remetidas pela rádio cada quatro meses e pela televisão cada trinta dias.

A GEMa incumbe-se de fazer a verificação, principalmente com relação à televisão e particularmente no que diz respeito à execução e aos filmes norte-americanos.

A Sociedade tem procurado critérios adequados para a solução de problemas particulares.

Assim, é pràticamente impossível evitar o uso abusivo dos "tapes", "cassetes", aparelhos gravadores de música, etc.

Prefere, por isso, estabelecer uma espécie de taxa relativa ao direito de autor sôbre o valor exclusivamente dog aparelhos vendidos em público para uso privado.

Para a sua arrecadação as três sociedades de direito autoral alemãs formam um escritório central, distribuindo-a entre si, na base de $40 \%$ para a GEMA; $40 \%$ para os artistas executantes e $20 \%$ para os autores de obras literárias.

A fiscalização exige um serviço muito extenso, com direções regionais nas principais cidades.

No que diz respeito ao uso comercial, os restaurantes, bares, etc., devem pagar um direito de execução na base de $100 \%$ sôbre o qual é calculado um acréscimo de $50 \%$ a título de execução mecânica pelo uso de gravadores, tapes, etc.

Com relação às gravações privadas, distribuídas como direitos mecânicos, pagam 100 de direito de execução, mais uma sobretaxa de 50 para a reprodução da gravação mecânica. 
Havendo execução sem programa, o pagamento é feito na base de:

$60 \%$ dos direitos mecânicos em geral;

$75 \%$ dos direitos mecânicos rádio;

$25 \%$ dos direitos mecânicos fono.

Um milhão de marcos por ano é arrecadado apenas em matéria de gravações, distribuído na base de $50 \%$ aos produtores fonográficos, e $50 \%$ aos artistas executantes.

Para as gravações com finalidades comerciais, diretamente da rádio ou por meio de discos, a fim de serem executadas em bares, dancings, cabarés, etc., existe uma tarifa para o direito de execução por meios mecânicos, recaindo sob a rubrica de direito de execução.

Se é o proprietário ou concessionário de estabelecimento quem faz a gravação, paga um suplemento de $50 \%$ para remuneração do direito mecânico.

Do montante encaminhado à GEMA, ela paga fono (discos) $25 \%$ como direito de autor, produtor e artistas intérpretes; $75 \%$ de direitos mecânicos: rádio e execução mecânica.

Para as demais gravações que não discos nem fitas, a GEMA tem percebido um suplemento de $20 \%$ para artistas executantes e produtores de fonogramas.

A distribuição do numerário é feita pelo correio ou por meio dos bancos, uma vez por ano em tôdas as secções, com exceção dos direitos mecânicos sonoros, em que é feita duas vêzes.

Com relação aos produtores fonográficos, a cobrança relativa à edição é feita diretamente junto à firma, com o que se poupam despesas de administração.

Dois funcionários fazem a verificação das contas na fábrica, existindo para a repartição dos direitos um serviço especial.

Sistema de trabalho. Assinale-se, antes de mais nada, que um dos fatores da organização da GEMa é a nenhuma 
interferência dos autores na gestão da sociedade. Todos os funcionários, mesmo os mais graduados, como o Presidente, os Diretores de Secção, etc., são condignamente remunerados, não podendo porém ser sócios nem ordinários, nem extraordinários. Os sócios apenas podem fazer parte das comissões especiais.

Por outro lado, não existe, como na SiaE ou na SgaE, corte de programas em "cupons" para a formação dos fichários relativos à contabilidade das execuções: funcionários específicos anotam os dados necessários em fichas correspondentes.

A GEMa distribui aos interessados uma série de formulários impressos, relativos $\mathrm{a}$ :

1. Condições a serem preenchidas pelos filiados;

2. Contrato tipo com associações de transportes;

3. Pedido de autorização para a realização de espetáculos públicos;

4. Variedades em cabarés;

5. Música mecânica e radiodifusão;

6. "Dancings" por meio de aparelhos radiofônicos;

7. Caixas de música;

8. Música automática;

9. Música mecânica, quando o próprio interessado faz a gravação;

10. Rádio;

11. Rádio nos quartos dos hotéis;

12. Música sinfônica;

13. Música intercalada nas peças teatrais;

14. Música de cêna;

15. Direito de reprodução mecânica, com exceção para a indústria cinematográfica;

16. Casas públicas e restaurantes que fazem gravações; 
17. Modêlos de programas;

18. Tarifas ônibus: rádio-recepções e "cassetes";

19. Execuções ocasionais em restaurantes ou associações;

20. Variedades e circos;

21. Recepção rádio e recepção televisão;

22. Filmes sonoros para cinema com projeções ocasionais e habituais;

23. Execução de música, etc.

A ficha de trabalho para distribuição dos direitos do autor e do editor, contendo o número, ou código da obra passa por uma máquina eletrônica.

Para cada país é aberta uma nova ficha, visto que um disco pode ir para o estrangeiro, dando margem quando fôr aí vendido, a que o interessado receba uma participação.

$O$ registro das fábricas de discos é feito por meio das cópias para contrôle, que têm, ou melhor que contêm todos os elementos necessários ao trabalho dos computadores, que já são enviados preparados semestre por semestre.

Percorremos o extensíssimo fichário geral de obras, com classificação por compositor da Alemanha Ocidental e por compositores do mundo inteiro, para execução pública e para direito mecânico.

A Bema conta com um serviço IвM/360, para fazer todos os cálculos e com um IвM/2311, para o registro e verificação da qüota.

Outro elemento simplificador do trabalho de cálculo da distribuição do numerário decorre de não se indicar na ficha o valor de cada obra. Prefere-se atribuir-lhe um certo número de pontos, fazendo-se o cálculo no fim do ano.

Tôda percepção de música sinfônica resulta de uma conta. 
As percepções são distribuídas pelas obras executadas num concerto, estabelecendo-se distinção entre as várias categorias.

Se se trata por exemplo, de uma pequena obra cantada, ou de uma sinfonia, terá, digamos, 1008 pontos. Outra obra pode ter 24 pontos. Tôda a arrecadação, de qualquer tipo, é dividida pelo número total de pontos.

$\mathrm{E}$ às execuções que não obedecem ao programa, juntam-se também os pontos respectivos no mesmo cálculo.

A vantagem consiste em que, em vez de se fazer a conta programa por programa, faz-se apenas uma soma final, dividindo-se o número de pontos pelo número de peças executadas.

A fim de evitarem-se prejuízos, multiplica-se por três o número de pontos para as músicas ligeiras executadas em music-halls, cabarés etc., porque sua incidência é proporcionalmente maior.

A GEMA faz ainda uma distinção entre a valoração da obra e a valoração levando em conta a percepção.

Discos e Radiodifusoras. Os fabricantes de discos enviam, para cada registro e cada disco, uma ficha em dois exemplares, com todos os dados necessários, e obtêm a devolução da duplicata com autorização, no verso, para fabricar, ou para exportar para todos ou para determinado país.

O fabricante pode fazer tôdas as prestações de contas por meio de fichas perfuradas.

Tem êle um contrato geral, mas só pode fazer prevalecer os direitos que êste lhe autorga quando tenha cumprido as suas obrigações, inclusive no que diz respeito às anotações, antes de fazer a distribuição dos discos para venda.

A radiodifusora opera, no tocante a essa parte, além de com o disco, com o "prato" gravado. O "prato" difere da fita magnética em que os elementos nêle contidos são 
tomados diretamente, o que aumenta muito a velocidade da operação.

A fita gravada, como o prato, são utilizados para fazer o trabalho de distribuição dos direitos aos interessados, fazendo o computador o cálculo diretamente sôbre a fita gravada.

\section{Société des Auteurs, Compositeurs et Editeurs de Musique (SACEM).}

O dia 8 de julho foi dedicado à visita à SACEM, instalada à Rua Chaptal, n. 10, onde ocupa três amplos edifícios, um com sete e dois com seis andares cada um. Tão logo, porém estiver pronta sua séde, vai mudar para Neuilly.

Prestou-nos esclarecimentos e acompanhau-nos na visita a sra. Ginette Ducroux, delegada dos negócios estrangeiros.

A sociedade conta com 420 funcionários na séde e 136 agentes arrecadadores no interior do país, e elementos além mar. Recebem em geral remuneração fixa, mas alguns percebem, além dessa, uma retribuição que varia de acôrdo com o serviço apresentado e o domínio geográfico da sua circunscrição.

Arrecadação. A Sacem arrecadou, em 1969, um total de mais de 185.536.000 francos, correspondendo a US $\$$ 33.552.000. A contribuição vinda do estrangeiro, para êsse total, orçou em Fr. 31.021.000.

Assinale-se o progresso notável que se registra com relação ao ano de 1968 , em que a arrecadação havia sido de Fr. 163.590.000.

Tais montantes são alcançados graças à circunstância de que muitos poucos usuários deixam de pagar o direito de autor.

Por outro lado, as despesas de administração também registram diminuição de ano para ano, como se pode ver 
pelo seguinte quadro, que também consigna o aumento nos juros correspondentes às quantias em depósitos:

\begin{tabular}{|c|c|c|c|}
\hline & 1968 & 1969 & Diferença \\
\hline Despesas . ..... & $26,05 \%$ & $25,23 \%$ & $-0,82 \%$ \\
\hline \multirow{2}{*}{ Juros $\ldots \ldots \ldots$} & $4,06 \%$ & $4,77 \%$ & $+0,71 \%$ \\
\hline & $21,99 \%$ & $20,46 \%$ & $-1,53 \%$ \\
\hline
\end{tabular}

Estrutura. A direção da sociedade é formada pelos seguintes cargos: Diretor Geral, Diretor Jurídico, Delegado da Direção para Negócios Estrangeiros e Culturais, Negócios Gerais, Secretaria Administrativa, Negócios Estrangeiros, Contrôle Geral da Arrecadação, Chefe da Distribuição, Chefe da Documentação Geral, Chefe da Contabilidade, Caixa, Serviços Musicais, Serviços Jurídicos, Fichário das Contas Correntes, Informatística (antiga Mecanográfica).

Todos são funcionários da Sociedade, cujos Estatutos proíbem a qualquer sócio ocupar postos dessa natureza.

Mas, além da direção existe a administração da entidade, constituida por um Presidente, três Vice-Presidentes, um Secretário Geral, um Secretário-Adjunto, um Tesoureiro, um Tesoureiro-Adjunto e sete Administradores. Dêsses quinze cargos, cinco são ocupados por autores, cinco por compositores e cinco por editores.

Existem três categorias principais de sócios, além de uma que não goza dessa prerrogativa: a dos aderentes.

Estes não precisam preencher, o que só é admitido excepcionalmente pelo Conselho de Administração, tôdas as condições previstas para os estagiários. Não precisam provar que têm obras publicadas, bastando que demonstrem ter duas ou três registradas em discos, ou executadas em público, ou divulgadas pela rádio ou pela televisão, ou por qualquer grande estabelecimento, de modo que a veracidade da afirmação possa ser averiguada.

Nos têrmos do artigo $6 .^{\circ}, 3 .^{\mathrm{a}}$ alínea, do Regulamento, são membros da Sociedade, estando por êsse título, subme- 
tidos às mesmas obrigações dos Estagiários, mas não poderão ser admitidos na qualidade dêstes a não ser quando tenham preenchido tôdas as condições previstas pelos estatutos e pelo Regulamento Geral.

$\mathrm{O}$ aderente não poderá assinar nenhuma obra com um colaborador da sua categoria, autor ou compositor.

Participa, no entanto, a repartição dos proveitos nas mesmas bases e nas mesmas condições dos sócios.

a) Estagiário. Todo candidato a autor ou compositor deve, nos têrmos do artigo 11 do Regulamento Geral, passar por um exame, que consiste:

Para o Autor, em escrever uma canção de duas cópias e de um refrão, uma poesia de forma clássica, um poema em versos livres, um monólogo, "sketch" de 10 a 15 minutos;

Para o Compositor, em desenvolver e harmonizar por escrito, sôbre 16 medidas pelo menos, um motivo dado, concebido no caráter das obras que figuram no "dossier" do postulante;

Para o Melodista, em escrever um canto sem acompanhamento sob tema dado. Não poderá ser admitido na qualidade de Melodista senão o candidato precedentemente admitido na qualidade de Autor Societário.

Poderá ser dispensado de qualquer exame o postulante que tenha uma notoriedade bem estabelecida e cuja admissão seja considerada útil ao interêsse social. Torna-se

b) Estagiário profissional, nos têrmos do artigo 25, mediante parecer favorável do Conselho de Administração, provando: I. ser estagiário ha mais de dois anos; II. ter recebido, no curso de cada dois anos anteriores, uma soma de direitos de execuções públicas igual à soma que é fixada para cada ano no início do exercício pelo Conselho de Administração. Passa a :

c) Sócio definitivo, também mediante parecer favorável do Conselho de Administração: 
1. Salvo derrogação excepcional, ser francês ou pertencente a país em que a sociedade exerce diretamente sua percepção;

2. Ter sido admitido na qualidade de Estagiário profissional há pelo menos três anos;

3. Ter recebido da Sociedade, no decurso de cada um dos três anos anteriores, determinados montantes de direitos autorais;

4. Não ter sofrido do Conselho de Administração, qualquer medida disciplinar no curso dos três anos anteriores.

Repartição dos direitos. Realiza-se na base da declaração das obras e da sua inclusão tanto na lista dos interessados, como nas fichas do repertório social.

O cálculo do valor da execução das obras musicais, vocais, ou instrumentais é feito, em princípio, com base numa divisão em seis partes, salvo principalmente os trêchos que não excedam de um minuto, que serão taxados no máximo em três ou em seis partes, conforme comportem ou não palavras e música.

São taxadas em seis partes as obras do repertório de duração de um a cinco minutos e que não entrem numa das categorias a seguir definidas.

São taxadas em nove partes as obras de duração de cinco a seis minutos e meio: pequenas "ouvertures", grandes marchas, grandes valsas a números, quadrilhas, andantes, adágios, curtas peças sinfônicas, prelúdios, peças de piano ou outros instrumentos, adaptações (melodromas); atrações, pequenos côros, melodias ou árias de óperas; extratos de sonatas; trios, quartetos, quintetos etc.

São taxadas em doze partes tôdas essas obras que tenham duração de seis minutos e trinta segundos a oito minutos.

Existe, em seguida, uma taxação de 18 a 102 partes, sem consideração ao gênero de todos os trêchos com dura- 
ção de 8 a 50 minutos, e uma taxação das obras literárias (sainetes, poemas, monólogos e duos).

A repartição é minuciosamente regulada pelos artigos 52 - 75 do Regulamento Geral.

Com relação ao estrangeiro, são reconhecidos $50 \%$ aos titulares dos direitos originários e $50 \%$ aos sucessores ou cessionários da edição.

Casos especiais: execuções por meio de discos em estabelecimentos públicos. Os bares, cafés, etc. terão que pagar à SAcEm dois direitos: um pela execução, outro pela utilização do disco. No futuro, quando venham a ser cobrados pela SACEM também os direitos dos artistas e intérpretes, terá que ser atendida também essa terceira categoria.

A SACEM não impõe contratos-tipo. Não porque não aprove o sistema, mas porque as diversas categorias de interessados não chegaram ainda a uma solução ideal.

Juke-Boxes. Problema relacionado com o anterior. Para dizer da sua importância basta lembrar que existem 25.000 dessas máquinas instaladas em tôda França.

A dificuldade que apresenta resulta da inexistência de programas que permitam controlar as execuções.

Antigamente procedia-se a um complicado e dispendioso sistema de escuta. Verificada a impossibilidade de controlar as milhares de máquinas em que são solicitadas as músicas mais diferentes, o sistema foi abandonado por dois motivos: 1. para diminuir as despesas; 2. por ter-se averiguado que muitas das relações enviadas continham dados falsos ou inexatos.

Hoje realiza-se o sistema por amostragem ou sondagem: sôbre cada 100 máquinas, "leitores" de pontos efetuam uma verificação durante duas horas em dez aparelhos, fazendo-se no fim do ano uma relação de tudo o que se executou.

Operam-se então cálculos que levam em conta o número de máquinas, a espécie do estabelecimento, o tamanho da cidade, etc., fazendo-se a repartição de acôrdo com os dados fornecidos por êsses dez aparelhos, que são generalizados. 
A segunda investigação será feita sôbre outros dez, e assim sucessivamente, de maneira que, dentro de um determinado período, todos os aparelhos são comprovados.

Para corrigir os efeitos do azar, aplicam-se fórmulas matemáticas, destinadas a eliminar as obras em "fim de carreira" e a substituí-las pelas que acompanham as preferências do público.

Música viva: bailes, etc. A repartição dos direitos autorais é mais fácil, pois os estabelecimentos transmitem música de acôrdo com programas impressos, fornecidos pela sociedade, à qual, depois de executados são devolvidos.

Houve, porém, como em tôda parte, falsificações, beneficiando autores ou composições.

A SACEM selecionou, então, 1800 chefes de orquestras entre os mais idôneos, aos quais, em vez de módulos a serem preenchidos, entrega cadernos em que já vêm anotados os nomes das composições mais conhecidas, cuja execução é assinalada com um simples traço, de cada vez. No final dos cadernos existem espaços em branco, a fim de serem apontadas composições solicitadas que não constam do rol.

De acôrdo com a maior ou menor intensidade das execuções, os cadernos são devolvidos mensal, bimensal ou trimestralmente.

Existem fiscais também para êsse serviço.

Se o chefe de orquestra não obedece às instruções, perde o privilégio, e fica obrigado a preencher novamente os programas, o que dá muito mais trabalho.

$\mathrm{E}$ se de todo não fornecer sequer o programa? Fica sujeito às sanções previstas no regulamento, entre as quais, pagar em dôbro o direito autoral.

Os cálculos para cobrança dos direitos autorais são feitos pela SACEM com fundamento em minuciosos elementos consignados em três livros de fôlhas sôltas, para facilitar a atualização, procurando levar em conta todos os dados ponderáveis: população da cidade em que se executa 
o número, importância do estabelecimento, prêço cobrado pelos aperitivos etc. .

Com relação à rádio e à televisão, a cobrança é feita com base em programas organizados e enviados pelas entidades respectivas.

As demais execuções musicais, em que não existe programa prévio, também são calculadas de acôrdo com um sistema de sondagens, que, com base no número de discos mais vendidos realiza cálculos matemáticos minuciosos, que permitem uma correção de êrros, na base mais rigorosa possivel.

Todos os dados colhidos são computados eletrônicamente.

Até 1967 o trabalho era feito pelo modo tradicional.

De então para cá começaram os trabalhos para implantação de um sistema eletrônico mais evoluído, denominado de "Terceira Geração", que permite, o que não ocorre com o da "Segunda Geração", efetuar várias operações ao mesmo tempo.

Todos os programas são transferidos em "Quotas", e são modificados, efetuando-se então os agrupamentos para chegar a codificações separadas de cada uma das execuções.

O Código das Obras, o Código das Repartições e as respectivas qüotas são transferidos para o prato magnético, apurando afinal o computador eletrônico o número de pontos a que faz jús cada obra.

A SACEM conta com um da "Terceira Geração", marca Borroughs, de média potência, com capacidade de gravar na "memória" 19.200 posições ou caracteres, registrando-se diretamente os programas na fita magnética.

É suficiente dar o número do programa, para que a máquina faça todo o trabalho de seleção.

Enquanto que o sistema da "Segunda Geração" grava sòmente 800 programas, correspondentes a 800.000 caracteres sôbre cada fita magnética, o da "Terceira Geração" grava vinte milhões de caracteres em cada fita. 
Existem em funcionamento na SACEM vinte aparelhos de uma terceira marca, também norte-americana: o MsD, que constitui a perfuração pelo registro direto na banda ou "tape magnético".

Foram êsses os elementos fundamentais que pudemos colher nessa visita sumária, que estabeleceu um importante primeiro contacto com o que de mais moderno se pratica, na Europa, em matéria de arrecadação do direito de autor.

$O$ relato outro objetivo não tem senão o de prestar serviço a quem tiver, no futuro, a responsabilidade de lançar as bases de um sistema de cobrança de direitos autorais mais digno e mais condigno com as nossas tradições, nessa matéria de fundamental importância para o progresso cultural do País.

É-me grato o ensejo, Senhor Ministro, para reiterar a Vossa Excelência os meus protestos da mais elevada consideração. 